\title{
INNOVATIVE AND Social TECHNOLOgIES ARE ReVolutionizing SAUdi Consumer AtTitude TOWARDS ElECTRONIC COMMERCE
}

\author{
Fahim Akhter \\ Management Information Systems Department, College of Business Administration, \\ King Saud University, Saudi Arabia
}

\begin{abstract}
The Internet today connects about $40 \%$ of the world population. Half of these are living outside the advanced economies, often in some countries that are quickly climbing the developmental ladder, with diverse populations and inarguable economic potentialities including Saudi Arabia. There are 20 million Internet users in Saudi Arabia by the end of 2016. This research examines the impact of the Internet, innovation, disruption and the dynamics that affect adoption of electronic commerce (e-commerce) in Saudi Arabia. The study further analyzes the influence of Internet security and its impact on the users' decision-making process. The data have gathered through questionnaires that disseminated to 2,823 Saudi Internet male and female users through email. The response rate was $23 \%$. The important findings have discussed in this study that shows that there are significant factors that are influencing the adoption of ecommerce, including legal procedures to ease of doing business, ease of doing businesses and security features and controls introduced by the online vendors.
\end{abstract}

\section{KEYWORDS}

Electronic Commerce, Internet, Online Shopping, Saudi Arabia, Security, Privacy

\section{INTRODUCTION}

The previous research [Akhter 2016, Balasubramanian, 2016] has endorsed the factors that influence the adoption of e-commerce, including trust, security, and privacy of the users. The trust is a critical non-technological factor for e-commerce success. The 20 million Saudi users understand the importance of the Internet and benefits of shopping online, including convenience, comparison, product research, larger selection, and lower prices. However, the buying decision may influence by many factors such as usability, security, privacy, lack of live interactions, and conducting business with unknown parties. Also, Saudi entrepreneurs have prospered despite Internet constraints. Entrepreneurs have been able to set up small-medium businesses, many accessing customers, and suppliers through the Internet.

Online consumers have many online alternatives to make sensible and safer buying decisions [Akhter 2006]. These buying decisions do potentially influence by a variety of factors such as security, familiarity, design, competitiveness, brand, reputation, third party seal, privacy, and presentation [Najlaa et al 2016]. Consumers consciously or subconsciously analyze and compare all these factors to decide whether to purchase from the particular website or else to move on to the following website. Due to the emergence of Internet technologies, trust and competitiveness in e-commerce are becoming the focal point of continuous research. 
A user often relies on experience and applies vague and ambiguous terms when making a buying decision. Upon executing a transaction, user actions are based on common sense and prior knowledge, rather than on the availability of clear, concise and accurate data. Intelligent systems do apply for reasoning about inherently vague concepts [Akhter, 2006], such as "online shopping is safe," where the level of safety is open to interpretation.

The purpose of the present study is to utilize the Saudi online user's perspective towards the issues and factors, including security and privacy that influence consumers' decision processes. This study used 20 closed ended questionnaires to collect the data as an appropriate means to understand how the users perceive and evaluate e-commerce. The rest of this paper comprises as follows. The paper begins by introducing the literature review, research methodology, followed by the analysis of the data. The implications of the results presented, and the paper concluded by highlighting key aspects of the study.

\section{LITERATURE}

There are many narrow and broad definitions of e-commerce; in general, it is defined to mean "goods and services transacted over the Internet." It covers transactions regarding business-tobusiness (B2B) or business-to-consumer (B2C). There are websites to order products in an online way, which is widely known as e-commerce [Vysotska et al. 2016]. B2B e-commerce is the electronic exchange of information, digital products, and services between companies and across the supply chain. In this form of commerce, all the appropriate documents are traded digitally rather than physically. The involved parties could have previous knowledge of each other and the opportunity to calculate how to share the risks involved in the project. Both sides could have employed legal expertise who could assist in arranging a best possible agreement be signed.Ecommerce security involves wider ranges like data security, computer security, and other related forms of information security framework. E-commerce includes providing security to users for daily business transaction [Kumar and Goyal 2016]. Online consumer's concerns regarding security affect purchase behavior. These concerns are more likely to raise the high-risk perception and lower buying behavior due to lower consumer trust in e-commerce [Vakeel 2016]. It is reported that success and failure of electronic commerce business depend on security and privacy issues and for this, users' trust is essential for development in e-commerce business [Chatterjee 2015]. There are different elements of security that are required to be in place to foster confidence in e-commerce, including integrity, non-repudiation, authentication, confidentiality, auditing, privacy, and availability. These elements create the instant online trust once in place to secure the transactions and information.

The rationale why Saudi consumers and businesses are still concerned about e-commerce is the perceived security risks associated with conducting online business. Online users consciously or subconsciously analyze the provided level of security based on their experience to decide whether to business with the particular company or else to move on to the next company. Akhter [2016, 2006], describe how e-commerce contains barriers to its growth and development, such as the lack of standardized technologies for secure payment and lack of proven online business models. Akhter and Albalawai [2016] believe that security is a dominant concern for vendors in the B2C e-commerce since it reflects the perception of consumers towards the business. Due to the uncertainty and complications that are present in online business, consumers are wondering whether their personal financial information such as credit card numbers are safe when they send it to a vendor over the Internet. The acceptance of B2B e-commerce in the Middle East and especially in the Saudi Arabia is the best example to support this claim. The table 1 from Live Internet Stats has illustrated the overall Internet penetration in Saudi Arabia. Internet penetration is extremely high in Saudi Arabia, especially when compared to other countries in the Middle 
East. Approximately 20,813,695 Saudis use the Internet, which is about a $64.7 \%$ penetration rate. This rate has rapidly grown from just 63\% in 2014 (table 1).

\begin{tabular}{|c|c|c|c|c|c|c|c|}
\hline Year & $\begin{array}{c}\text { Internet } \\
\text { Users }\end{array}$ & $\begin{array}{c}\text { Penetration } \\
(\% \text { of Pop) }\end{array}$ & $\begin{array}{c}\text { Total } \\
\text { Population }\end{array}$ & $\begin{array}{c}\text { Non-Users } \\
\text { (Intemet } \\
\text { less) }\end{array}$ & $\begin{array}{c}\text { 1Y User } \\
\text { Change }\end{array}$ & $\begin{array}{c}\text { 1Y User } \\
\text { Change }\end{array}$ & $\begin{array}{c}\text { Population } \\
\text { Change }\end{array}$ \\
\hline 2016 & $20,813,695$ & $64.7 \%$ & $32,157,974$ & $11,344,279$ & $2.8 \%$ & 561,748 & $1.96 \%$ \\
\hline 2015 & $20,251,947$ & $64.2 \%$ & $31,540,372$ & $11,288,425$ & $2.9 \%$ & 577,218 & $2.12 \%$ \\
\hline 2014 & $19,674,729$ & $63.7 \%$ & $30,886,545$ & $11,211,816$ & $7.7 \%$ & $1,403,093$ & $2.27 \%$ \\
\hline
\end{tabular}

Table 1 Internet adoption in Saudi Arabia - 2017

\section{Methodology}

One-hundred and twenty questionnaires were chosen out of 826 responses for further study. The response rate was $29 \%$. They were asked to express the extent of their agreement or disagreement with a number of statements on online business infrastructure and practices in Saudi Arabia. The aims of this research are to generalize Internet users" attitudes and expectations about ecommerce and to identify the ways in which a sense of trustworthiness achieved and sustained. The researcher conducted a survey of Internet users who were asked to share their e-commerce experiences and expectations to accomplish the purposes. The poll did conduct through email until September 21, 2016, and January 14, 2017. The researcher used the SPSS statistical package to analyze the responses to the questionnaires. The respondents were asked 20 questions, investigating the importance of security, privacy and cultural in online business, covering topics such as users' experiences with online shopping; Saudis' most trusted websites; expectations towards assurance and security controls and ease of use of the website. A pilot test was conducted to examine the instrument before collecting data. The purpose of the pilot test was to access whether the instruments were capturing the phenomena desired.

The researcher used simple random sampling because of the process of random selection of the sample, which removes the possibility of biases. Any differences that do occur are then the results of chance rather than bias on the part of the researcher. The key to obtaining a random sample is to ensure that every member of the population has an equal and independent chance of being selected. The researcher, achieved this objective by using a table of random numbers. According to Fraenkel [2005], the advantage of random number sampling is that, if large enough, it is very likely to produce a representative sample.

\section{RESULTS AND DISCUSSION}

A total of 20 questions was involved, with the objectives of assessing: the respondent background and expertise in the e-commerce; perception towards doing online business and concerns; and respondent's security concerns in online business. It recommended that subject's responses interpreted as indicative rather than definitive opinions from the Saudi Arabia business community. Most respondents believe that Internet usage is a valuable tool for their business and personal needs and provides a competitive advantage. The figure 1 showed that Saudi women are progressively active online as compared to male users. 


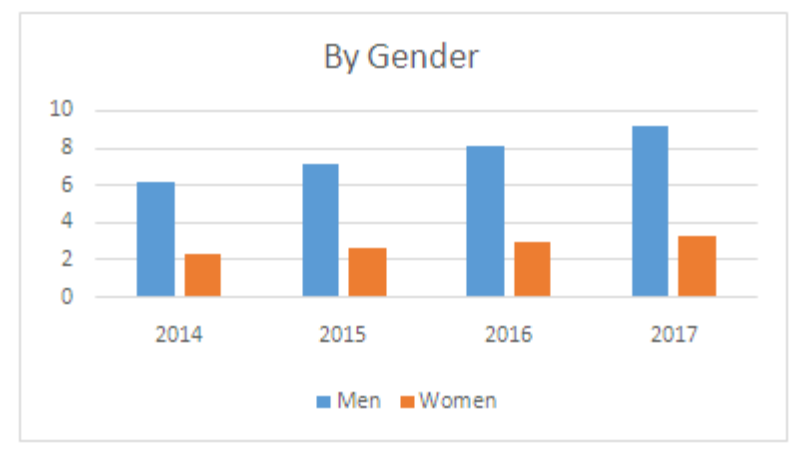

Figure 1 Internet Users by Gender

Some questions were posed concerning the security implementation online business. The results suggested that users have positive perceptions towards e-commerce because it is more convenient, access to wider selection and faster turnaround. Some responses suggest that attractiveness of online offers and the access to a wider range of suppliers are some of the reasons for them to adopt B2C e-commerce. Most respondents made a comment regarding the rationale for adopting B2C e-commerce where access to a global market, possibilities for attractive presentation and cost. The figure 2 reveals that Saudi age between 25-34 is progressively embracing e-commerce to meet daily and business needs. This trend will boost the e-commerce once this group becomes more authoritative in making strategic decisions in Saudi corporations.

The Saudi users are enjoying the experience of online shopping while quickly returned or canceling their orders. The statistics showed that $38 \%$ of cases, customers return the product or cancel their ordered because they changed their mind and didn't want it anymore. The online shopping experience has a positive future in Saudi Arabia, which does strengthen by $71 \%$ of respondents who were satisfied with their online shopping experience. The future of e-commerce is very promising while Saudi users have more than 12 million of credit and debit cards to shop online.

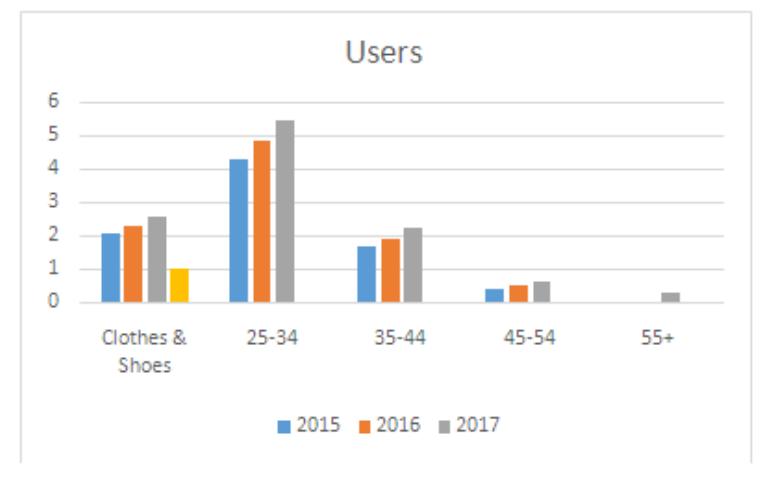

Figure 2 E-commerce users by Age Group in millions

Approximately half of the respondents claimed to engage in $\mathrm{B} 2 \mathrm{C}$ e-commerce activities. However, when asked to rate the hacking concerns of these online activities, more than $50 \%$ were not affected. This lack of interest is both surprising and worrying, and it reflected that such views would be unlikely to give confidence to Saudi customers. A secure website has become a critical e-business issue. The risks of computer hackers, online theft, and intrusion by competitors and other vulnerabilities are influencing the growth of B2C and B2B. A statistic from this study showed that $25 \%$ of entrepreneurs are worried that company's online transactions could hack. 
Online companies tend to use a digital signature as a public key cryptography to ensure the integrity of an online document. Digital signatures also provide on- repudiation protection because digitally signed documents cannot have signatures denied successfully. Figure 3 showed a progressive increase in e-commerce revenue in different categories, including clothing \& shoes, consumers electronic, foods \& pharmaceuticals and furniture \& home appliances. The projected revenue shows the upwards trend in the year 2017 and beyond. The source of income for online vendors comprised of clothes \& shoes and consumer electronic categories. It supports the perception that users are looking high-quality products at lower prices from the comfort of homes and offices.

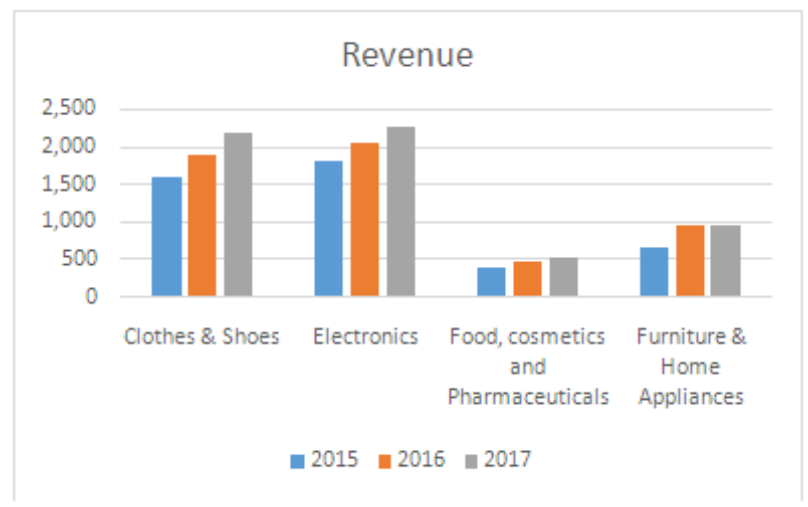

Figure 3 E-commerce revenue by category

It suggested that a lack of security is not the only barrier, but consumer trust can also play a significant role in encouraging and credible e-commerce. Some of the respondents made comments that online business could grow much faster in Saudi Arabia if appropriate infrastructures implemented through which vendors' and users' security issues remain addressed. In this way, both parties would assure that conducting online business transactions are safe and protected by the appropriate technology embedded within systems. The embedded technologies such as Secure Electronic Transactions (SET) and Secure Socket Layer (SSL) have succeeded in their aim to provide safer and easier use of conducting online transactions. SSL is a mechanism for securing online transactions and can provide two protections, such as encryption of the communication link, and confirmation that the contacted server belongs to the vendor. This mechanism is desirable from the consumer security perspective. A more resolute alternative for SSL is SET which provides considerably more protection. The obvious trust-building factor between SSL and SET from the user perspective is that credit card details about them not revealed to the vendors. That immediately enhances the consumer's trust level by reducing the potential for threats such as data streaming, as merchant systems would no longer accumulate card details. SET also offers advantages to the vendor, in the sense of being able to authenticate the identity of the customer.

The majority of this list is typical of any country, with Google and various social media pages dominating the list of most visited websites. However, it is also an exciting list for those wishing to invest in e-commerce in Saudi Arabia. Two of the top ten websites - haraj.com.sa and souq.com are e-commerce websites. Haraj.com.sa is an online auction website and souq.com is a general online store for the Middle East that is much like amazon.com and eBay. The presence of these two sites on this list suggests large-scale confidence in online transactions and that Saudis are ready and able to engage in online markets. 
International Journal of Security, Privacy and Trust Management (IJSPTM) Vol 6, No 1, February 2017

It suggested during the surveys that the entrepreneurs must adopt and integrate information systems to facilitate the Internet in its business processes across functional units, using a shared database. The adoption of the e-commerce will enable the decision-making process to be timely, consistent and reliable across organizational units and geographical locations. The respondents believe the globally adopted e-business model is evolving around the adoption of the Internet. Respondents have suggested that there are several barriers besides security and privacy, which deter to conduct business electronically. Also, local norms of doing business include consumer resources, age, knowledge, lifestyle, educational level, attitude, motivation, marital status, personality, values, and cultural values, could have weights in influencing a consumer's buying decision. For example, the attitude of consumers towards online shopping in developed countries such as the UK or the U.S. may be different from users from less developed countries such as Pakistan, Bangladesh, United Arab Emirates and Saudi Arabia.

\section{CONCLUSION}

E-commerce forecast in Saudi Arabia has been overwhelmingly positive both regarding recent growth and prospects. B2C commerce would have a great potential for growth in Saudi Arabia if security implementation considered seriously. Vendors should adopt policies that enhance the perception of assurance and trust by clearly stating returns policies; options for cancellation of an order without penalty, special offers, and ease-of-use of company websites as these are particularly successful at building consumers trust. It is vital for websites to be endorsed by third parties for reliability such as Visa, MasterCard, VeriSign, or TRUSTe. A secure website is a requirement for consumers and companies to provide credit card numbers to online companies. However, a deterrent to e-commerce growth in Saudi Arabia has been a dependency on an unreliable and costly payment method. Many users have used a cash delivery method due to mistrust in payment systems. Trusted third party endorsements and digital signature feature widely accepted among consumers. Also, companies must ensure that their client's information remains secure and intact. In summary, security and trust remain major concerns for e-commerce and validated by the survey statistics. Some companies do not have substantial knowledge about the process when they purchase online products and services. What companies hear from the media most often are security breaches and frauds, and the consequences create an environment of distrust. Users who prefer to adopt B2B commerce might be afraid to conduct transactions because they feel it is not safe and given information to businesses can be obtained from other companies and hackers. If e-commerce is to become the dominant business platform in Saudi Arabia, then it must allow companies to place complete trust in the confidentiality, security, integrity, and availability of information processed and stored in every aspect of online economies.

In 2017, The World Bank group report has assigned a ranking of 94 out of 189 countries to Saudi Arabia on "Ease of Doing Business." Even though the ranking improved by 2 points from last year, it suggests that current business procedures have the potential of improvement to attract foreign business community. For example, its take a long waiting period of 19 days and overcome 12 legal procedures for small-to-medium businesses to startups. The improved legal systems could enhance the online business startups in Saudi Arabia. The government has taken initiatives to address the regulations and business frameworks. These actions will speed up to locate reliable shipping services, ascertain that a website is in accordance with Saudi law, and protect users' rights. The government interest in overhauling the procedures and provide support to users and businesses is received as a great interest in from e-commerce entrepreneurship. 
International Journal of Security, Privacy and Trust Management (IJSPTM) Vol 6, No 1, February 2017

\section{ACKNOWLEDGEMENT}

The author extends his appreciation to the Deanship of Scientific Research at King Saud University, represented by the Research Centre at the College of Business Administration, for funding this research.

\section{REFERENCES}

[1] Akhter, F, (2006). The Impact of Foreign Languages, Customs, Business Policies, and Infrastructure Factors on the Growth of B2C E-Commerce. In IADIS International Conference e-Commerce. Barcelona, Spain.

[2] Akhter, F, (2016). Cultural Dimensions of Behaviors Towards E-Commerce in a Developing Country Context" International Journal of Advanced Computer Science and Applications, 7 (4).

[3] Akhter, F, Albalawai, W, (2016). Online Trust and Young Entrepreneurs: A case Study of Saudi Arabia, International Journal of Theoretical and Applied Information Technology, E-ISSN $1817-$ 3195, 2016.

[4] Chatterjee, S., "Security and privacy issues in E-Commerce: A proposed guideline to mitigate the risk," in Advance Computing Conference, 2015 IEEE International, vol., no., pp. 393-396, 12-13.

[5] Fraenkel, J, and Wallen, N. (2005). How to Design and Evaluate Research in Education. Sixth Edition, McGraw-Hill Publishing Company.

[6] Nielsen/Net Rating and International Telecommunications Union (2005). The Big Picture http://www.internetworldstats.com/stats.htm last accessed March 29, 2007.

[7] V. Vysotska, L. Chyrun and L. Chyrun, (2016) "Information technology of processing information resources in electronic content commerce systems," 2016 International Scientific and Technical Conference Computer Sciences and Information Technologies, Lviv, pp. 212-222.

[8] Kumar, D, and Goyal, N, (2016). "Security issues in M-commerce for an online transaction," 2016 5th International Conference on Reliability, Infocom Technologies and Optimization, Noida, pp. 409414.

[9] Balasubramanian, K. (2016). Threats and Attacks on E-Commerce Sites. In Cryptographic Solutions for Secure Online Banking and Commerce (pp. 70-89). IGI Global.

[10] NajlaaAlMajed, Leandros A. Maglaras, Francois Siewe, Helge Janicke, PoonehBagheriZadeh, "Prevention of crime in B2C E-Commerce: How E-Retailers/Banks protect themselves from Criminal Activities", EAI Transactions on Security and Safety, Volume 3, Issue 7, December 2016

[11] Vakeel, K. A., Das, S., Udo, G. J., \&Bagchi, K. (2016). Do security and privacy policies in B2B and B2C e-commerce differ? A comparative study using content analysis. Behaviour\& Information Technology, 1-14. 